\title{
Genetic Diversity Analysis of "Murungakayan" Rice Accessions based on Seed Morphology and Molecular Characterization
}

\author{
M.M.S.L. Manatunga, S.K. Wasala ${ }^{1 *}$, V.A. Sumanasinghe ${ }^{2}$ and N.M. Ubeysekara ${ }^{1}$ \\ Postgraduate Institute of Agriculture \\ University of Peradeniya \\ Sri Lanka
}

\begin{abstract}
Genetic diversity of germplasm among species and within the species is important for systematic conservation of genetic resources. This study was conducted to assess the genetic diversity and to identify similar groups among the twenty-seven Murungakayan accessions conserved at the gene bank of Plant Genetic Resource Centre, Gannoruwa. Seed morphological characterization was done according to the standard descriptors for rice and data were analysed using Minitab 15.1. Molecular assessment was done using 31 SSR markers and PCR amplified products were resolved using 8\% polyacrylamide gel electrophoresis. Bands were manually scored and analyzed using PowerMarker version 3.25. Morphological analysis grouped these accessions into ten clusters. The molecular analysis based on SSR markers generated 108 alleles across 27 populations. Polymorphism Information Content values ranged from 0.00 (RM 518 and RM 237) to 0.72 (RM 515) which revealed high genetic diversity. Nei's genetic distance among accessions ranged from 0.00 to 0.9 and a dendogram grouped the accessions into eight clusters. Four sets of duplicates were identified with high genetic similarities. According to the molecular and morphological analyses, accessions 3490, 5378, 5614, 6279, 12824, 3329, 3491 and 5611 can be identified as the representative set of Murungakayan with high similarity. The results suggested that microsatellite markers along with morphological data could be used for identification of the representative set of Murungakayan accessions for systematic conservation and utilization.
\end{abstract}

Keywords: Duplication, genetic variation, Murungakayan, SSR diversity

\section{INTRODUCTION}

Landraces of rice play a very important role as the main staple food, in addition to their significance as a genetic resource for rice genetic improvement (Tang et al., 2002). Presently most of the rice lands in Sri Lanka (99\%) are cultivated with New Improved Varieties (NIVs). At a minor extent, some traditional and old improved varieties are cultivated in the country (Rajapakse et al., 2000). The Plant Genetic Resource Centre (PGRC) explored and conserved the genetic resources of rice including traditional cultivars, wild relatives, old improved and exotic germplasm. Out of catalog of 14310 conserved accessions at PGRC, 4924 accessions were Oryza spp. Among them 684 were traditional varieties which include 2407 accessions (Gene bank information PGRC, 2017). Traditional rice cultivars continue to

\footnotetext{
1 Plant Genetic Resources Centre, Department of Agriculture, Gannoruwa, Sri Lanka

2 Department of Agricultural Biology, Faculty of Agriculture, University of Peradeniya, Sri Lanka

* Corresponding author: samanthiwasala@yahoo.com
} 
have a good and increasing market value (Wickramasinghe and Noda, 2008; Suriyagoda et al., 2011) due to their antioxidant properties and high nutritional value (Premakumara et al., 2013). Murungakayan is one of the popular traditional rice varieties with high nutritional value. Based on the Ayurvedic literature it was extensively recommended for pregnant mothers. Its nutritional values were considered conducive for the growth of the fetus and relieving the mother at her confinement (Withanawasam, 2017). There are 27 Murungakayan accessions available at PGRC. Accessions used in this study have been collected from different parts of the country hence there is a significant variation observed among them. Majority of them are spindle-shaped with red seed coat color.

The seed bank of PGRC, accessions are conserved by the vernacular name given by farmers. Therefore, the same cultivar may have been conserved under different names or conversely different cultivars under the same name. Study of genetic diversity among accessions appearing with the same cultivar name is critically important for systemic conservation and utilization of plant genetic resources. These genetic variabilities can be analyzed based on morphological and molecular data. Morphological data are the basis for the early and preliminary level of diversity analysis. Since molecular markers are independent of environment effects they can assist in the analysis of genetic relatedness and the identification and selection of desirable genotypes for crosses as well as for systematic germplasm conservation in gene banks. On the other hand, due to the high demand for traditional rice cultivars, Department of Agriculture plans to certify popular traditional cultivars with minimum standards for seed production. For that correct identification of a representative set of accessions for the cultivar is a prerequisite. Accordingly, the aim of this study is to identify the diversity among 27 Murungakayan accessions and to determine a representative set of accessions for seed production.

\section{METHODOLOGY}

\section{Experimental site and plant materials}

This study was conducted at the Biotechnology division of Plant Genetic Resource Centre (PGRC), Gannoruwa, Peradeniya. Seeds of 27 Murungakayan rice accessions were obtained from the gene bank of PGRC. Accession number, accession name of the material used and its origin and organization collected from are given in Table 1.

\section{Seed morphological and molecular characterization}

Seven qualitative and quantitative data were recorded. Seeds were evaluated based on the seed shape, color and pubescence of lemma and palea, seed coat color, sterile lemma color, grain length and grain width. Characterization was done according to the descriptors of rice (IPGRI Database, 2017). DNA was extracted using modified CTAB (Cetyltrimethylammonium bromide) method optimized at PGRC, Gannoruwa (Wasala et al., 2017). Two grams of three-week old immature leaves from 27 plants were sampled to represent the whole population. Raw DNA was confirmed in $0.8 \%$ agarose gel and quantified by comparing with the band intensity of $25 \mathrm{ng} \lambda$ DNA and concentration of DNA was adjusted to $20 \mathrm{ng} / \mu \mathrm{l}$.

Based on the grouping of accessions by seed morphology data, different bulks were prepared by pooling equal amount of DNA from each accessions for the convenience and for the cost 
effectiveness. A set of optimised 31 SSR markers (Temnykh et al.,2000) were selected for the molecular characterization.

Table 1: Details of plant materials used in this study

\begin{tabular}{|c|c|c|}
\hline Accession Number & Accession Name & Organization \\
\hline 3257 & Murungakayan & Unknown \\
\hline 6283 & Murungakayan & CRBS \\
\hline 5610 & Murungakayan & CRBS \\
\hline 3855 & Murungakayan & Unknown \\
\hline 3809 & Murungakayan & Unknown \\
\hline 3900 & Murungakayan & Unknown \\
\hline 3921 & Murungakayan & Unknown \\
\hline 3490 & Murungakayan 101 & Unknown \\
\hline 5611 & Murungakayan 101 & CRBS \\
\hline 5612 & Murungakayan 104 & CRBS \\
\hline 3495 & Murungakayan 104 & Unknown \\
\hline 3489 & Murungakayan 3 & Unknown \\
\hline 5614 & Murungakayan 302 & CRBS \\
\hline 5613 & Murungakayan 302 & CRBS \\
\hline 3329 & Murungakayan 302 & Unknown \\
\hline 5378 & Murungakayan 302 & ARS / AT \\
\hline 3492 & Murungakayan 303 & Unknown \\
\hline 3491 & Murungakayan 304 & Unknown \\
\hline 3328 & Murungakayan 307 & Unknown \\
\hline 3331 & Murungakayan 308 & Unknown \\
\hline 6280 & Murungakayan 101 & CRBS \\
\hline 6284 & Murungakayan 101 & CRBS \\
\hline 6281 & Murungakayan 104 & CRBS \\
\hline 6279 & Murungakayan 3 & CRBS \\
\hline 6285 & Murungakayan 3 & CRBS \\
\hline 6282 & Murungakayan 303 & CRBS \\
\hline 12824 & Murungakayan & \\
\hline
\end{tabular}

Polymerase chain reaction was performed according to the protocol optimized at PGRC (Wasala et al., 2012). A $15 \mu$ l of PCR reaction mixture was prepared for each DNA bulk and for BG 360 which was used as the standard accession. Amplification profile consisted of five touchdown cycles where annealing temperature was reduced by $2^{\circ} \mathrm{C}$ at each cycle using 
Takara Thermal Cycler Dice Touch (Code.TP350). PCR products were confirmed using 1.5 $\%$ agarose gel electrophoresis and resolved using 8\% (Acrylamide: Bis of ratio 29:1) non denaturing polyacrylamide gel electrophoresis in $1 \mathrm{X}$ TBE buffer. Finally, bands were visualized under UV light using a gel documentation system (BIO-RAD) with the help of Quantity One software. If there were more than one band available within the bulk, they were expanded and rerun.

\section{Data analysis}

Cluster analysis was done using MINITAB 15.1. Gel images were scored manually by visual observation as presence (1) and absence (0) of every allele for all SSR markers. Scored data were analyzed using PowerMarker version 3.25 and MEGA 6.06. Major allele frequency, allele number, PIC value and gene diversity, were calculated across the population to identify the prevailing genetic diversity. Nei's genetic distance (1983) was calculated among the accessions. Phylogenetic tree was constructed by using Nei's genetic distance and Unweighted Pair Group Method with Arithmetic Mean (UPGMA) algorithm. Finally, representative set was selected placing more emphasize on molecular data.

\section{RESULTS AND DISCUSSION}

\section{Morphological analysis}

A majority of morphological traits showed variation among accessions. Seed shape ranged from half spindle shape $(6-7 \mathrm{~mm})$, spindle shape $(7-8 \mathrm{~mm})$ to very spindle shape $(>8 \mathrm{~mm})$. Most of the Murungakayan accessions displayed short pubescence on lemma and palea. One accession (AC: 3900) showed pubescence only on the upper portion. Four accessions (AC:6283, 5610,3855 and 3329) showed long pubescence. AC 3900, 3328, 3331 have brownish black furrows on the straw background while AC 3921, 5611, 3492 and 6280 have yellowish brown colored lemma and palea. In seed coat color, AC 3328 is having off white seed coat while rest of them have red color. AC 3331 and 3495 have both red and off white color seed coat but the majority are red in color (Table 2). Based on the morphological analysis 27 accessions were clustered into ten groups at more than $75 \%$ similarity level. According to the dendrogram most distantly related accession was AC 3328 which has white seed coat. Most closely related accessions were AC 5611 and AC 6280 followed by AC 3921 and AC 6281.

\section{Molecular analysis}

\section{Allelic diversity}

The 31 SSR markers revealed a total of 108 alleles. It ranged from 1 to 5 per locus. Percentage polymorphism was $93.5 \%$. It shows high diversity among the Murungakayan accessions. Two primers, namely RM 518 and RM 237 were monomorphic for all 27 accessions. The mean genetic diversity ranged from 0 (RM 518 and 237) to 0.76 (RM 515) with the mean value of 0.49 . The PIC (Polymorphic Information Content) values for the primers ranged from 0 (RM 518 and 237) to 0.72 (RM 515) indicating that high diversity exists among individual accessions having even the same cultivar name. Higher major allele frequency is recorded in the RM 237 and RM 518 as 1.00 and lower major allele frequency is recorded as 0.32 for primer RM 418 and RM 515 (Table 3). 
Table 2: Seed morphological data of accessions coded as per rice descriptor; 2017

\begin{tabular}{|c|c|c|c|c|c|c|c|}
\hline Ac No & $\begin{array}{l}\text { Grain } \\
\text { shape }\end{array}$ & $\begin{array}{c}\text { Lemma } \\
\text { and } \\
\text { palea } \\
\text { color }\end{array}$ & $\begin{array}{l}\text { Seed } \\
\text { coat } \\
\text { color }\end{array}$ & $\begin{array}{c}\text { Sterile } \\
\text { lemma } \\
\text { color }\end{array}$ & $\begin{array}{l}\text { Pubescence } \\
\text { of lemma }\end{array}$ & $\begin{array}{c}\text { Grain } \\
\text { width(mm) }\end{array}$ & $\begin{array}{c}\text { Grain } \\
\text { length } \\
(\mathrm{mm})\end{array}$ \\
\hline 3257 & 5 & 4 & 5 & 1 & 4 & 2.004 & 9.414 \\
\hline 6283 & 4 & 0 & 5 & 1 & 5 & 1.964 & 8.5 \\
\hline 5610 & 5 & 14 & 5 & 1 & 5 & 1.938 & 9.646 \\
\hline 3855 & 4 & 1 & 5 & 1 & 5 & 2.008 & 8.798 \\
\hline 3809 & 4 & 0 & 5 & 1 & 4 & 2.06 & 8.884 \\
\hline 3900 & 4 & 18 & 5 & 1 & 3 & 2.024 & 8.52 \\
\hline 3921 & 4 & 13 & 5 & 1 & 4 & 1.99 & 8.764 \\
\hline 3490 & 5 & 4 & 5 & 1 & 4 & 1.994 & 9.144 \\
\hline 5611 & 4 & 13 & 5 & 1 & 4 & 1.956 & 8.702 \\
\hline 5612 & 5 & 4 & 5 & 1 & 4 & 2.032 & 8.97 \\
\hline 3495 & 5 & 4 & 5 & 1 & 4 & 2.152 & 8.942 \\
\hline 3489 & 5 & 0 & 5 & 1 & 4 & 1.986 & 9.128 \\
\hline 5614 & 4 & 0 & 5 & 1 & 4 & 1.972 & 8.766 \\
\hline 5613 & 4 & 4 & 5 & 1 & 4 & 1.968 & 8.364 \\
\hline 3329 & 5 & 16 & 5 & 1 & 5 & 1.662 & 8.912 \\
\hline 5378 & 5 & 4 & 5 & 1 & 4 & 2.098 & 8.906 \\
\hline 3492 & 4 & 13 & 5 & 1 & 4 & 2.168 & 8.836 \\
\hline 3491 & 4 & 4 & 5 & 1 & 4 & 2.026 & 8.428 \\
\hline 3328 & 4 & 18 & 0 & 1 & 4 & 2.062 & 8.642 \\
\hline 3331 & 4 & 18 & 5 & 1 & 4 & 2.154 & 8.486 \\
\hline 6280 & 4 & 13 & 5 & 1 & 4 & 1.94 & 8.808 \\
\hline 6284 & 4 & 1 & 5 & 1 & 4 & 2.016 & 8.894 \\
\hline 6281 & 4 & 12 & 5 & 1 & 4 & 2.014 & 8.852 \\
\hline 6279 & 4 & 4 & 5 & 1 & 4 & 2.042 & 8.602 \\
\hline 6285 & 4 & 1 & 5 & 1 & 4 & 1.964 & 8.366 \\
\hline 6282 & 4 & 1 & 5 & 1 & 4 & 2.064 & 9.178 \\
\hline 12824 & 3 & 12 & 5 & 1 & 4 & 1.918 & 7.61 \\
\hline
\end{tabular}

Grain shape: 1-Round,2-semi round,3-half spindle shape,4-spindle shape,5-very spindle shape. Lemma palea color: 0-straw,1-gold furrows on straw background,2-brown spots on straw,3-brown furrows on straw,4-brown,5-reddish to light purple,6-purple spots on background,7-purple furrows on straw back ground,8-purple,9-black,10-white,11-brownish black,12-yelowish grey,13-yellowish brown,14-brown furrows on gold background,15reddish brown spots on gold background,16-black spots on straw background,17-brownish black furrows on gold back ground,18-brownish black furrows on straw background,19brown furrows on yellowish background. Seed coat color: 0-off white,1-white,2-light brown,3-speckled brown,4-brown,5-red,6-variable purple,7-purple,8-off white with black apiculus,9-off white with brown apiculus,10-brown seed coat with white strip,11-red seed coat with white strip,12-off white seed coat with white strip with black apiculus,13-off white seed coat with white strip,14-brown seed coat with black apiculus,15-light brown seed coat with white strip,16-brown seed coat with white strip and black apiculus. Sterile lemma color: 1-straw, 2-gold, 3-red, 4-purple. Pubescence of lemma: 1-glabrous,2-hair on lemma keel,3hair on upper portion,4-short hairs,5-long hairs. 
Table 3: Descriptive data analysis for 31 SSR primers across 27 Murungakayan accessions.

\begin{tabular}{|c|c|c|c|c|}
\hline Marker & $\begin{array}{c}\text { Major Allele } \\
\text { Frequency }\end{array}$ & $\begin{array}{c}\text { Allele } \\
\text { No }\end{array}$ & $\begin{array}{c}\text { Gene } \\
\text { Diversity }\end{array}$ & $\begin{array}{c}\text { PIC } \\
\text { Value }\end{array}$ \\
\hline RM 215 & 0.54 & 3 & 0.57 & 0.49 \\
\hline RM 571 & 0.54 & 4 & 0.61 & 0.56 \\
\hline RM 518 & 1.00 & 1 & 0.00 & 0.00 \\
\hline RM 213 & 0.86 & 3 & 0.25 & 0.23 \\
\hline RM 236 & 0.89 & 3 & 0.20 & 0.19 \\
\hline RM 560 & 0.57 & 4 & 0.58 & 0.52 \\
\hline RM 224 & 0.86 & 3 & 0.26 & 0.24 \\
\hline RM 216 & 0.61 & 4 & 0.57 & 0.52 \\
\hline RM 202 & 0.68 & 3 & 0.46 & 0.38 \\
\hline RM 20B & 0.50 & 4 & 0.63 & 0.57 \\
\hline RM 480 & 0.54 & 4 & 0.56 & 0.47 \\
\hline RM 208 & 0.61 & 3 & 0.54 & 0.47 \\
\hline RM 237 & 1.00 & 1 & 0.00 & 0.00 \\
\hline RM 207 & 0.43 & 5 & 0.71 & 0.67 \\
\hline RM 84 & 0.54 & 4 & 0.56 & 0.47 \\
\hline RM 515 & 0.32 & 5 & 0.76 & 0.72 \\
\hline RM 536 & 0.54 & 4 & 0.61 & 0.55 \\
\hline RM 255 & 0.46 & 4 & 0.66 & 0.60 \\
\hline RM 241 & 0.86 & 3 & 0.25 & 0.23 \\
\hline RM 259 & 0.75 & 4 & 0.41 & 0.38 \\
\hline RM 217 & 0.71 & 3 & 0.45 & 0.40 \\
\hline RM 440 & 0.50 & 4 & 0.59 & 0.51 \\
\hline RM 228 & 0.79 & 4 & 0.36 & 0.34 \\
\hline RM 219 & 0.46 & 3 & 0.56 & 0.47 \\
\hline RM 270 & 0.43 & 4 & 0.62 & 0.55 \\
\hline RM 412 & 0.43 & 3 & 0.63 & 0.55 \\
\hline RM 220 & 0.57 & 4 & 0.59 & 0.54 \\
\hline RM 201 & 0.50 & 3 & 0.56 & 0.47 \\
\hline RM 25 & 0.64 & 3 & 0.48 & 0.40 \\
\hline RM 418 & 0.32 & 5 & 0.74 & 0.70 \\
\hline RM 539 & 0.68 & 3 & 0.48 & 0.42 \\
\hline Mean & 0.62 & 3.48 & 0.49 & 0.44 \\
\hline
\end{tabular}

\section{Genetic distance}

Based on Nei's genetic distance (Nei's,1983), genetic distance ranged from 0.9 to 0.0 . Maximum distance (0.9) was recorded between two sets. (Bg 360 - AC 6283 and Bg $360-$ AC 3331). Since Bg 360 is an improved variety its genetic distance showed higher values from the rest of the Murungakayan accessions. Four sets of accessions were identified with high genetic similarities. 


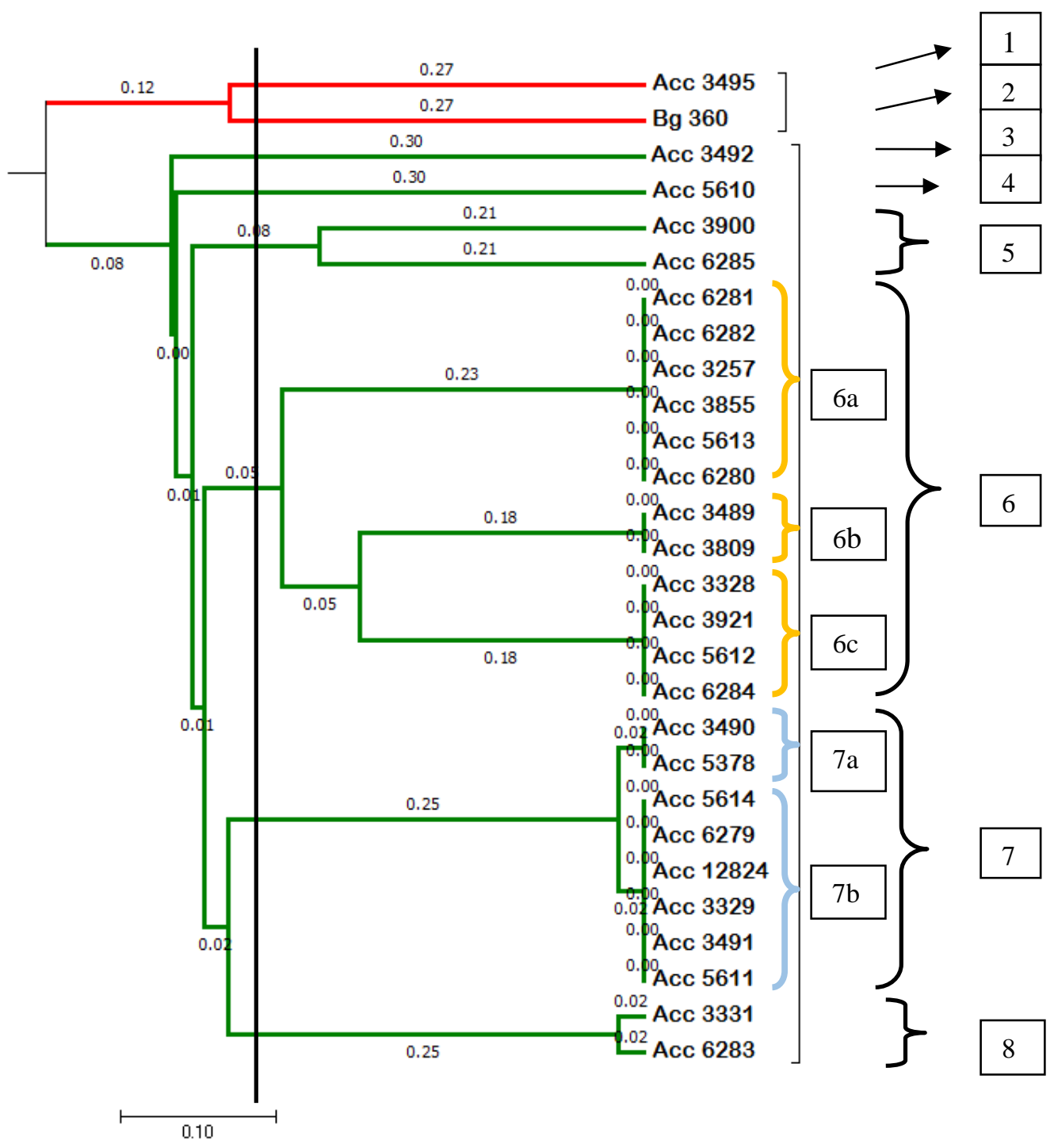

Figure 1: Phylogenetic tree constructed based on Nei's genetic distance

1-Cluster 1, 2-Cluster2, 3-Cluster3, 4-Cluster4, 5-Cluster5, 6a- First sub cluster of 6, 6bSecond sub cluster of $6,6 \mathrm{c}$ - Third sub cluster of $6,7 \mathrm{a}$ - First sub cluster of 7, 7b-Second sub cluster of 7, 8- Cluster 8

According to the constructed phylogenetic tree all individuals can be grouped into eight main clusters (Figure 1). Bg 360 and accessions 3495 were clustered separately exhibiting a vast genetic diversity among them. AC 3495 and $\mathrm{Bg} 360$ deviated from the rest of the accessions with the genetic distance of 0.39 and made two separate clusters. (Cluster $1 \& 2$ ). AC 3492 and 5610 showed 0.3 genetic distance and made cluster 3 and 4 . Cluster 6 contained $44.4 \%$ of total accessions. Cluster 6 can be divided into 3 main sub clusters (Sub cluster $6 \mathrm{a}, 6 \mathrm{~b} \&$ 6c). In cluster 7 accessions 3329, 12824, 6279, 5614, 5611, 3491 were grouped separately (7b) and 5378 and 3490 made a minor sub cluster (7a). 
During this study, a significant degree of genetic diversity was observed among the accessions. Compared to the genetic diversity analysis of traditional rice varieties in Sri Lanka such as Pokkali, Suwandal, Kuruluthuda and Kaluheenati, Murungakayan shows a number of similarity groups. There were no such similarity groups observed in Suwandal (Wasala et al., 2017), four pairs of similar groups were observed in Pokkali and Kaluheenati (Thotagodawatta et al., 2017; Siriwardhana et al., 2016), and one pair of genetically similar accession was identified in Kuruluthuda. (Karunadasa et al., 2017) However, when comparing genetic diversity, Murungakayan is having higher diversity $(0.00-0.76)$ than Kaluheenati (0.110-0.70) but similar genetic diversity in Kuruluthuda (0.30-0.79) and Pokkali (0.33-0.77). Therefore, they have been subjected to selections when compared to other traditional rice varieties as they have been collected from farmers from all over the country. Based on the summary statistics higher major allele frequency was recorded in the SSR markers RM 237 and RM 518 as 1.0 which shows that they are monomorphic. Murungakayan 302 was the parental line of H-4, which was an old improved verity. H-4 is the first bred variety in Sri Lanka with wide adaptability and resistant to bacterial leaf blight (RRDI database). During this study four accessions (AC 5613, 5378, 5614, 3329) of Murungakayan 302 line has been studied. Based on molecular analysis three of them (AC $5378,5614,3329$ ) are grouped into cluster 7 and the other accession (AC 5613) grouped separately into the cluster 6 showing that there is genetic variation present in the same line. Considering morphological and molecular analysis accessions: 3490, 5378, 5614, 6279, 12824, 3329, 3491 and 5611 are identified as the representative set of Murungakayan for systematic utilization.

\section{CONCLUSIONS}

The present study exhibited that there is a significant variation among 27 Murungakayan accessions. Giving more emphasize to molecular analyses eight accessions namely 3490, $5378,5614,6279,12824,3329,3491$ and 5611 having closer relatedness to each other were selected as the representative set of Murungakayan which can be used as donor parents in breeding programs, seed production and certification.

\section{REFERENCES}

International Plant Genetic Resources Institute (IPGRI) Data base,2017.

Premakumara, G.A.S., Abeysekera, W.K.S.M., Ratnasooriya, W.D., Chandrasekharan, N.V. and Bentota, A.P. (2013). Antioxidant, anti-amylase and anti-glycation potential of brans of some Sri Lankan traditional and improved rice (Oryza sativa L.) varieties. Journal of cereal science, $58,451-456$

Rajapakse, R.M.T., Sandanayake, C.A. and Pathinayake, B.D. (2000). Foot prints in rice variety improvement and its impact on rice production in Sri Lanka. Annual symposium of the Department of Agriculture, Sri Lanka, 2, 423 - 433.

Rice Research and Development Institute Batalagoda Data base,2017.

Karunadasa R.M.S.P and Samarasinghe W.L.G. (2017). Genetic diversity analysis of traditional rice variety Kuruluthuda using SSR markers. Proceeding of the international research symposium, Uva wellassa university, Sri Lanka, (1), 192 
Siriwardhana, S.M., Samarasinghe, W.L.G. and Gimhani, D.R. (2016). Molecular characterization of a traditional rice variety Kaluheenati (Oryza sativa L.) using simple sequence repeats markers. Proceedings of 15th Agricultural Research Symposium. Faculty of Agriculture and Plantation Management, Wayamba University of Sri Lanka, 135-139.

Suriyagoda, L.D.B., Thilakarathne, R.M.M.S., Nissanka, S.P., and Samita, S. (2011). Morphological variation in selected rice (Oryza sativa L.) germplasm of Sri Lanka, Journal of the National Science Foundation of Sri Lanka 39(2): 129-137.

Tang, S. X., Y. Z. Jiang, X. H. Wei, Z. C. Li and H. Y.Yu. (2002). Genetic diversity of isozymes of cultivated rice in China. Acta Agron. Sin., 28: 203-207

Temnykh, S.,W.D. Park, N. Ayres, S. Cartinhour, N, Hauck, L, Lipovich, Y.G. Cho, T, Ishii, and S.R, McCouch, 2000. Mapping and genome organization of microsatellite sequences in rice (Oryza sativa L.). Theor. Appl. Genet. 100:698-712.

Thotagodawatta, T.M.N.B.K., Samarasinghe, W.L.G., Alwis, L.M.H.R. and Ubeyasekara, N.M. (2017). Genetic diversity analysis of traditional rice variety Pokkali using simple sequence repeat markers (SSR). Proceeding of the international research symposium, Uva wellassa university, Sri Lanka, (1) 190

Wasala, S.K., Senanayake S.R.T.P. and Wanigadewa S.M.S.W. (2012). DNA fingerprinting of traditional rice (Oryza sativa L.) accessions for diversity analysis and cultivar identification. Annual of the Sri Lanka Department of Agriculture. 14,187-196

Wasala, S.K., Hennayake, H.M.K.N.K., Gunasena, P.G.S.D., Rebeira, S.P., Kondasinghe, K.M.C.L., Danwatta, A.S.J. and Ubeyasekara N.M. (2017) Assessment of genetic diversity among Suwandal rice (Oryza sativa L.) accessions based on morphological, molecular and physiochemical characteristics: Tropical agriculturist. 165,113-130

Wickramasinghe, H.A.M., Noda, T. (2008) Physicochemical properties of starches from Sri Lankan rice varieties, Food Science and Technology Research 14(1): 49-54.

Withanawasam D.M (2017) Cyber extension: Heritage of heirloom rice verities of Sri Lanka [Accessed on 15.03.2018] Available at: https://www.doa.gov.lk/rrdi/images/Mydoc/publication1.pdf 